\title{
Is fine needle aspiration thyroid cytology (THY status) a good prognostic indicator of definitive histological diagnosis?
}

\author{
Milhan Bahar, Vinay Varadarajan, Antonio Belloso
}

Blackburn Royal Hospital UK.

\begin{abstract}
Although recently published research has focused on the addition of ultrasound scan findings to the evaluation of the thyroid gland, FNAC has long been the corner stone of thyroid lesion decision making. In our study population of 100 thyroidectomies we found out of those who had a cytological diagnosis of Thy 2 and underwent thyroidectomy due other compounding factors $8.57 \%$ of the had malignancy reported in their final histology report. We also found that a Right-sided solidarity thyroid nodule in a male may be an increased risk factor for malignancy. We highly recommend addition of USS staging to be included in decision making especially in benign lesions as there is still a significant risk of malignancy.
\end{abstract}

\section{Introduction.}

Fine needle aspiration cytology (FNA/ FNAC) is considered the gold standard diagnostic test for the diagnosis of thyroid enlargement. Fine needle aspiration cytology is a cost effective procedure that provides specific diagnosis rapidly with minimal complications. ${ }^{1,2}$ Based on the cytology findings, patients can be followed in cases of benign diagnosis and subjected to surgery in cases of malignant and suspected non diagnostic findings thereby decreasing the rate of unnecessary surgery. The Purpose of the present study was to correlate the fine needle aspiration cytology findings with histopathology of excised specimens ${ }^{3,4}$

\section{Ethical Clarence}

Ethical clearance was obtained from the Audit department, East Lancashire Health trust.

\section{General objectives}

1. To compare outcomes of FNAC against final Histological diagnosis

\section{Specific Objectives}

1. To compare outcomes of Thy 2 against final Histological diagnosis

2. To compare outcomes of Thy 3 against final Histological diagnosis

3. To compare outcomes of Thy 4 against final Histological diagnosis

4. To compare outcomes of Thy 5 against final Histological diagnosis

\section{Material and Methods.}

- Place

o ENT UNIT East Lancashire Hospital Trust (ELHT), Royal Blackburn Hospital.

\section{- Study Population}

o ELHT covers population of 650000 and almost all head and neck cancer surgical care is given at Royal Blackburn Hospital. In this study the sample population is 2000, which is statistically significant number.

o Thyroid surgeries are mainly performed by Head \& Neck Surgeons who are attached to ENT department.

\section{- Study period-}

o January 2014 -December 2014 


\section{- Study design-}

o Descriptive cross sectional and is retrospective descriptive comparative study in patients who underwent diagnostic and therapeutic thyroidectomy with FNA investigation.

\section{- Inclusion criteria}

o Patients who have had thyroid surgery performed in the form of total or hemi thyroidectomies

o Patients having ultrasound scan reports

o Patients having with FNAC reports

\section{- Exclusion criteria}

o Patients not operated within the trust - East Lancashire Hospital Trust (ELHT), Royal Blackburn Hospital

\section{- Data Collection}

o A random list of patients was generated from a total population of patients who underwent thyroidectomy surgery at Blackburn Royal Hospital UK.

o The data collected by overseas ENT Senior Clinical Fellow, Registrars and Middle grade doctors

o The research data is collected from different sources.

- Case notes

- Syngoplaza computer network radiology image system

- ICE computer network system

\section{- Analysis}

o The collected data was tabulated in a Microsoft Excel worksheet. Statistical analysis was performed on Microsoft Excel as well.

\section{Results.}

The total study population was 100 . The mean age of the patient population was 44.04 and the sex ratio male to female was 0.12 to 0.88 .

All patients in this study underwent some form of surgical intervention. 92\% of the surgeries performed were hemi thyroidectomies and the remaining (8\%) were total thyroidectomies. Of the hemi thyroidectomies 36\% were right sided and 56\% were left-sided. (Chart 2)

70 patients were found have Thy 2 as their preoperative FNAC result. Thy 3, Thy 4 and Thy 5 were 24, 4 and 2 respectively (Table 1 ).

\begin{tabular}{|l|c|}
\hline \multicolumn{1}{|c|}{ Thy } & $\begin{array}{c}\text { Number of } \\
\text { patients }\end{array}$ \\
\hline Thy 2 & 70 \\
\hline Thy 3 & 24 \\
\hline Thy 4 & 4 \\
\hline Thy 5 & 2 \\
\hline Total & 100 \\
\hline \multicolumn{2}{|c|}{ Table $\mathbf{1}$} \\
\hline
\end{tabular}

$22 \%$ of all patients who underwent FNAC were found have malignant histology. All patients (100\%) who had Thy 4 and Thy 5 FNAC results had definitive malignancy reported in their histology samples. $41.67 \%$ of patients having Thy 3 FNAC had definitive malignancy reported on histology. Surprisingly $8.57 \%$ of patients having Thy 2 FNAC had definitive malignancy reported on histology. (Table 2)

\begin{tabular}{|l|c|c|c|c|}
\hline \multirow{3}{*}{ Thy } & $\begin{array}{c}\text { Be- } \\
\text { nign }\end{array}$ & $\%$ & Malignant & $\%$ \\
\hline Thy 2 & 64 & $91.43 \%$ & 6 & $8.57 \%$ \\
\hline Thy 3 & 14 & $58.33 \%$ & 10 & $41.67 \%$ \\
\hline Thy 4 & & $0.00 \%$ & 4 & $100.00 \%$ \\
\hline Thy 5 & & $0.00 \%$ & 2 & $100.00 \%$ \\
\hline Total & 78 & & 22 & \\
\hline
\end{tabular}

Table 2 
Milhan Bahar, Vinay Varadarajan, Antonio Belloso Is fine needle aspiration thyroid cytology (THY status) a good prognostic indicator of definitive histological diagnosis?

All male patients who had FNAC of Thy3 and above returned malignant histology. Conversely all male patients with Thy2 FNAC were found to have benign histology. All male patients having Thy3 or more on FNAC either had a right hemi thyroidectomy or a total thyroidectomy done, of these patients $75 \%$ of them had an initial presentation on the right thyroid lobe.

$70 \%$ of patients who underwent thyroidectomy surgery at this trust had THY 2 as their FNA result. And this figure increases to $78 \%$ once histology was analysed (benign histology). (Tables $1 \& 2$ )

\section{Discussion.}

Thyroid goitre was first identified in the $16^{\text {th }}$ century by Leonardo da Vinci and Andreas Versalius ${ }^{5}$. The procedure thyroidectomy did not become popular till 1909 when Theodore Kocher demonstrated a safe technique of extra capsular thyroidectomy. By 1920 safe and effective thyroid surgery had been broadly accepted ${ }^{6}$.

There are many indications for thyroid surgery. Thyroid malignancy or suspicion of thyroid malignancy being one of the most common. Below is a list of indications where one may consider thyroidectomy ${ }^{6}$.

Total thyroidectomy/completion thyroidectomy

1. Papillary carcinoma $>1 \mathrm{~cm}$

2. Medullary thyroid carcinoma

3. Follicular carcinoma $>1 \mathrm{~cm}$

4. Compression symptoms from a benign goitre

\section{Thyrotoxicosis}

Lobectomy and isthmusectomy

1. Thy3A, Thy3F lesion

2. Thy4 lesion _ FS

3. Recurrent cyst

4. Compression symptoms - asymmetric goitre +/-

\section{Retrosternal extension}

6. Growing/suspicious lesion despite benign cytology

From this it is abundantly clear that surgery/ thyroidectomy can be part of our treatment regime for benign thyroid disease. In our study $70 \%$ of patients underwent thyroidectomy procedure with an FNA of Thy 2.

When investigating a patient with thyroid enlargement FNAC is now the cornerstone of investigation ${ }^{7}$. The Betheshda System of reporting is now standard for most of the laboratories around the world ${ }^{7}$.

Thy 1 - Inadequate for diagnosis

Thy 2 - Benign Disease

Thy 3 - Suspicious of neoplasia

Thy 4 - suspicious of malignancy

Thy 5 - Positive for malignant disease

Published studies have shown despite FNA categorising thyroid disease into the above category there can still be a risk of malignancy even though the FNA shows benign disease. This can be seen from the below displayed study results $^{8}$.

\begin{tabular}{|l|c|l|}
\hline \multicolumn{1}{|c|}{ Diagnostic Category } & $\begin{array}{c}\text { Risk } \\
\text { of } \\
\text { Malignancy } \\
(\%)\end{array}$ & Usual Management \\
\hline Nondiagnostic or unsatisfactory & $1-4$ & $\begin{array}{l}\text { Repeat FNA with } \\
\text { ultrasound guidance }\end{array}$ \\
\hline Benign & $0-3$ & Clinical follow-up \\
\hline $\begin{array}{l}\text { Atypia of undetermined significance } \\
\text { or follicular lesion of undetermined } \\
\text { significance }\end{array}$ & $5-15$ & Repeat FNA \\
\hline $\begin{array}{l}\text { Follicular neoplasm or suspicious } \\
\text { for a follicular neoplasm }\end{array}$ & $15-30$ & Surgical lobectomy \\
\hline Malignant & $97-99$ & Near total thyroidectomy \\
\hline
\end{tabular}

In our study FNAC Thy 2 returning the definitive malignancy report stood at $8.5 \%$ which is significantly higher than the risk published in the above study. Our study also shows that hundred percent of patients who had Thy4 and Thy 5 FNA results had histology proven thyroid malignancies. 
The accuracy of FNA may be subject to variation. In a published study in 2013 it was concluded that if any as a diagnostic test suffers in accuracy which may affect its overall reliability ${ }^{9}$. Further literature review also shows if any findings of Thy3 only have a $55.3 \%$ chance of becoming proven thyroid cancers ${ }^{10}$. To improve the accuracy of FNA it is recommended that the proceeding be performed under ultrasound guidance with a pathologist in attendance to assess sample adequacy ${ }^{11}$.

To help with decision-making in performing a thyroidectomy on a patient with benign FNA but suspicious clinical features the British Thyroid Association now recommends that ultrasound staging (U staging) be performed ${ }^{12}$.

1.Normal thyroid gland (U1),

2.Benign nodule (U2),

3.Equivocal /indeterminate nodule (U3),

4. Suspicious(U4) and

5. Malignant nodule (U5)

When analysing the risk factors for thyroid malignancy standard text dictate that a nodule is more likely to be malignant if there is the following findings ${ }^{7}$

1. Positive family history

2. Previous history of thyroid cancer

3. Enlarging (particularly on suppressive doses of thyroxine)

4. The nodule develops under 14 or over 65 years of age

5. The patient is male

6. There is a past history of ionizing radiation

7. TSH is elevated

8. Thyroid antibodies are positive
Extrapolating data from our study, a solitary nodule presenting in a mere patient on the right side can also be considered a risk factor.

\section{Deficiencies}

1. A comprehensive review of preoperative ultrasound scans of all patients operated was not performed. Hence ' $U$ ' staging for the disease could not be analysed.

2. Sub classification of Thy 3 FNAC could not be obtained from the system.

3. Results of thyroid function tests as well as thyroid antibody tests were not available.

4. The sample size for this study may be inadequate therefore subjecting some variables to bias. A larger study with a bigger population may be required to further investigate our findings.

\section{Conclusions}

1. FNAC is the cornerstone for investigation of the thyroid nodule. Correlation of FNA findings with the probability of malignancy has been already published. In our study we found that malignant probability of Thy 2 to be slightly higher at $8.57 \%$ (compared to $3 \%)$

2. The chance of malignancy in Thy 4 and Thy 5 FNAs are significantly higher than published results further necessitating aggressive management. (Compared to 30\% and 99\% respectively)

3. Ultrasound staging of thyroid disease is recommended in the walk up when making a clinical decision to operate.

4. Right-sided solidarity thyroid nodule in a male may be an increased risk factor for malignancy 
Milhan Bahar, Vinay Varadarajan, Antonio Belloso Is fine needle aspiration thyroid cytology (THY status) a good prognostic indicator of definitive histological diagnosis? Volume : 5; Issue1; pp 19-23

\section{Tables}

\section{Table 3 - Male Patients}

\begin{tabular}{|l|r|}
\hline Thy Level & $\begin{array}{r}\text { Chance of Malig- } \\
\text { nancy on histology }\end{array}$ \\
\hline Thy 2 & $0.00 \%$ \\
\hline Thy 3 & $100.00 \%$ \\
\hline Thy 4 & $100.00 \%$ \\
\hline Thy 5 & $100.00 \%$ \\
\hline
\end{tabular}

\section{Figures and Illustrations.}

Chart 1

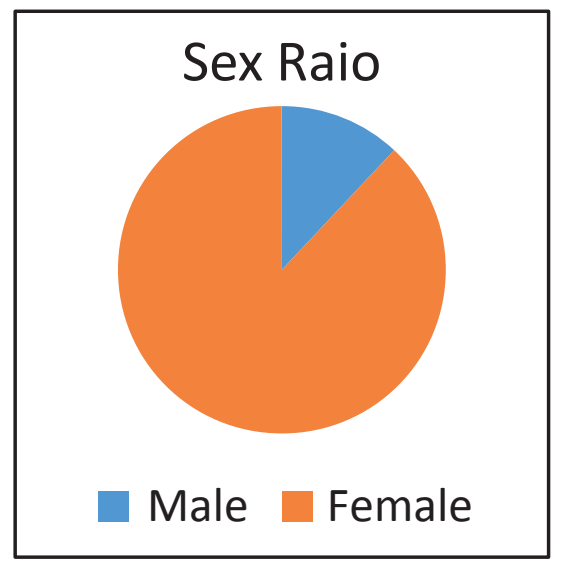

Chart 2

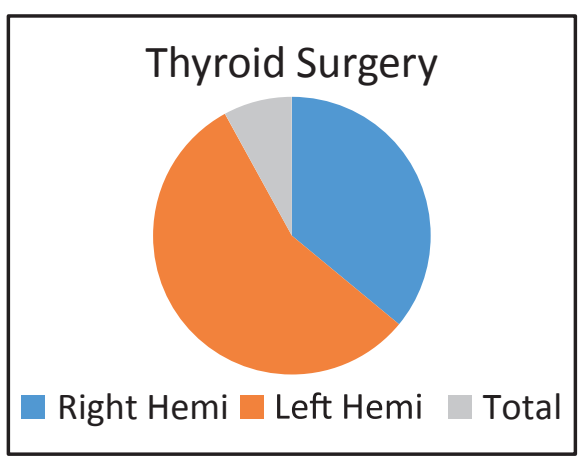

\section{References.}

1. Oertel,Y.C., "Fine-needle aspiration and the diagnosis of thyroid cancer," Endocrinology and Metabolism Clinics of North America, vol. 25, no. 1, pp. 69-91, 1996

2. Ridgway, E.C., "Clinical evaluation of solitary thyroid nodules," in The Thyroid: A Fundamental and Clinical Text, pp. 13771385, G. B. Lippincott, Philadelphia, Pa, USA, 1986

3. Bakhos,R.,Selvaggi,S.M.,DeJong,S. et al., "Fine needle aspiration of the thyroid: rate and ofcytopathologic discordance," DiagnCytopathol, vol. 23, no. 4, pp. 233-237, 2000.

5. Giddings, A.E., The history of thyroidectomy. J R Soc Med 1998;91(suppl 33): 3e6.

6. Shore,S.,Waghorn,A.J.W.et al, 'Thyroidectomy' Surgery International Vol 29.9 Sept 2011

7. Ramsden,J., Watkinson,J. C., 'Thyroid Cancer' Chapter 197, Scott Brown ENT 7E, , Page 2663.

8. Cibas, E.S., Ali, S.Z., The Bethesda System for Reporting Thyroid Cytopathology. Am J Clin Pathol 2009; 132: 658-665.

9. Schmidt et al,Appraisal of FNAC Diagnostic Accuracy Studies, Arch Pathol Lab Med-Vol 137, April 2013

10.Sandeep, G. Mistry, Navin Mani,Prad Murthy, 'Investigating the value of fine needle aspiration cytology in thyroid cancer' J Cytol. 2011 Oct-Dec; 28(4): 185-190.

11.Morgan, J.L.1., Serpell, J.W., Cheng, M.S., 'Fine-needle aspiration cytology of thyroid nodules: how useful is it? ANZ J Surg. 2003 Jul;73(7):480-3.

12.British Thyroid Association Guidelines for the Management of Thyroid Cancer, JULY 2014 